\title{
Do current indications for surgery of primary gastric lymphoma exist?
}

\author{
J. C. Rodríguez-Sanjuán, R. A. García, S. Trugeda, F. de la Torre, J. Llorca and M. Gómez-Fleitas \\ Department of General Surgery II. Hospital Universitario Marqués de Valdecilla. ${ }^{1}$ Department of Prevention and Public \\ Health. University of Cantabria. Santander, Spain
}

\begin{abstract}
Objective: to analyze the results of our series in order to assess whether surgical excision is still a valid therapeutic option in case the patient needs surgery. Secondarily, to analyze Helicobacter pylori infection rate.

Patients and method: a retrospective study of 69 consecutive patients having stage $\mathrm{I}_{\mathrm{E}}-\mathrm{II}_{\mathrm{E}}$ primary gastric lymphoma; of these, 65 were treated by gastrectomy between 1974 and 1999. Mean age: 62.6 years (28-85). New staining of paraffin-embedded samples from the surgical specimen were carried out (hematoxiline-eosine, Giemsa, immunohistochemistry) and reviewed. The histological classification was performed according to Isaacson's criteria. The statistical analysis was done by Chi-squared and Fisher's exact tests, as well as Kaplan-Meier and Log-Rank tests.

Results: mortality was 9.2\%. There were non-fatal complications in $10.8 \%$. Helicobacter pylori was identified in $62.7 \%$. Seven patients (11.9\%) suffered a relapse. The 5-year survival probability was $87 \%$. The statistical analysis did not show any influences of Ann Arbor stage, gastric wall invasion, Helicobacter pylori infection, histological type, or margin resection involvement on survival.

Conclusions: surgical excision provides a high rate of complete remissions and excellent long-term survival with acceptable mortality. Therefore it appears to be a valid treatment in case of emergency surgery, incidental finding, or lack of histological diagnosis.
\end{abstract}

Key words: Stomach lymphoma. Surgery.

Rodríguez-Sanjuán JC, García RA, Trugeda S, de la Torre F, Llorca J, Gómez-Fleitas M. Do current indications for surgery of primary gastric lymphoma exist? Rev Esp Enferm Dig 2006; 98: 180-188.

Recibido: 12-07-05.

Aceptado: 29-10-05.

Correspondencia: Juan Carlos Rodríguez-Sanjuán. Departamento de Cirugía General II. Hospital Universitario Marqués de Valdecilla. Avda. Valdecilla, s/n. 39008 Santander. e-mail: cgdrsj@humv.es

\section{INTRODUCTION}

Gastric lymphoma (GL) is a not very common tumor, having an incidence of 0.7-0.8 cases per 100,000 inhabitants in Western Europe (1). Its pathogenesis has been related in recent years to Helicobacter pylori (H. pylori) infection (2). Controversy exists concerning treatment since there are several therapeutic options. Surgery, the classical treatment with proven efficacy, is being displaced by chemotherapy (CT) (3-5) with encouraging results. The demonstrated relationship between GL and $H$. pylori led to these patients being treated exclusively with bacterial eradication therapy, achieving quite high complete remissions, although long-term outcomes are still uncertain $(2,6)$. These non-surgical therapies are currently considered the treatment of choice in most cases, but there are some clinical settings in which surgery still plays a role. Some of these are bleeding or perforation during CT (7), unresponsiveness to CT or $H$. pylori eradication therapy, the case of a gastric tumor with negative biopsies, as well as the incidental finding upon surgery. Outcomes after gastrectomy in GL have been satisfactory from an oncological point of view in our experience (8) and also in that of others (9-12), and therefore a surgeon may consider the option of surgical resection in the above-mentioned settings without fear of performing the wrong treatment.

On the other hand, the knowledge of prognostic factors can help define optimal therapy for individual cases. Reported factors include clinical stage, high-grade histological type (HG) according to Isaacson's classification, stomach serosa involvement, and PCNA expression $(2,8,10,13-15)$.

The main objective of this work was to analyze the most recent results of our clinical series of GL, and the prognostic value of several histological factors correlating them with postoperative survival, in order to establish whether surgical excision is still a valid option in the 
clinical settings where surgery could be necessary. As a secondary aim, we analyzed the prevalence of $H$. pylori infection.

\section{METHODS}

We performed a retrospective study of 69 patients diagnosed as having primary gastric lymphoma according to Dawson's criteria (16), in Ann Arbor stage $\mathrm{I}_{\mathrm{E}}$ and $\mathrm{II}_{\mathrm{E}}$ (17), between 1974 and 1999, who were treated by gastrectomy-with previous informed consent-at the time when surgery was considered the initial treatment of choice. The series consists of 36 women and 33 men with a mean age of 62.6 years (range: 28-85). Some of the patients were included in a previously published study (8).

In the first 15 patients of the series a diagnosis of gastric tumor was reached according to a barium upper gastrointestinal series. The diagnosis of GL was confirmed after histological analysis of the surgical specimen. In the remaining 54 patients, the diagnosis was done by gastroscopy and biopsy.

Staging was performed by physical exploration, peripheral blood study, chest X-ray, and bone marrow analysis in every case. In the earlier half of the series, the tumor was finally staged at celiotomy. After the introduction of computed tomography, it was used to stage the latest 23 cases. The stage was $\mathrm{I}_{\mathrm{E}}$ in $59.4 \%$ and $\mathrm{II}_{\mathrm{E}}$ in $39.1 \%$.

A patient was also diagnosed as having acquired immunodeficiency syndrome, and was previously published (18). Treatment consisted of surgical excision in 65 (94.2\%) and was non-surgical in 4-CT in $3(4.3 \%)$ and $H$. pylori eradication in $1(1.5 \%)$. Postoperative CT (consisting of $\mathrm{CHOP}$ ) was given to 32 patients, and postoperative radiotherapy (RT) was added to 4 . The study is focused on the 65 patients treated by gastrectomy. The tumor was located in the upper third in 4 patients, middle third in 27 , and distal third in 30, and involved the entire stomach in 4. Partial gastrectomy was performed in 48 patients and total gastrectomy in 17, according to the distance to cardia criterion. Splenectomy was added in 7 cases due to tumor proximity, although with no spleen involvement in any of them.

Radicality was R0 in 50, R1 in 12 and R2 in 3. There was no residual tumor in 50 cases (R0). Extragastric invasion was found in 3 patients: jejunum in one case and mesocolon in two. In one of the latter, a segmental resection of colon was added, and in the other a residual tumor was left (R2). Microscopic margin involvement was found in 12 cases (R1). There were non-fatal complications in 7 patients $(10.8 \%)$, and 6 died during the postoperative period $(9.2 \%)$.

In 60 cases histology was revised with new stains (hematoxiline-eosine, Giemsa) of paraffin-embedded specimen blocks. The immunohistochemical study was performed by means of the soluble complex alkaline phosphatase-antiphosphatase (Biomeda Corp., Foster
City CA, USA). A prediluted panel (all from Cormedica, Spain) was used, the common leukocyte antigen CD 45 being a marker for lymphocyte cells, L26 a marker for B phenotypic lymphocytes, and UHCL1 a marker for T phenotypic lymphocytes.

Tumors were sorted according to Isaacson's classification (19).

Statistical analysis was carried out using the Chisquared and Fisher's exact tests. The Kaplan-Meier and Log Rank tests were used for survival analysis. Patients who died in the first 30 postoperative days were excluded from the survival analysis. Patients dying from other causes or lost to follow-up were considered as censored.

\section{RESULTS}

Fifty-one cases could be classified according to Isaacson's classification: low-grade type B (LG) in 31 cases (61\%), high-grade type B (HG) in 18 (35\%), and type T in $2(4 \%)$. Wall involvement could be assessed in 60 cases: total in 36 cases $(60 \%)$ and partial in $24(40 \%)$. H. pylori was identified in 32 of the 51 cases analyzed $(62.7 \%)$. It was more common in LG tumors $(63.3 \%)$ than in HG tumors (58.8\%) (NS). Seven patients suffered from lymphoma recurrence (11.9\%). The 5-year survival probability (SP) was $87.93 \%$ (Fig. 1). The statistical analysis (Table I) only found significant influence on PS for the Ann Arbor stage. No influence was shown for gastric wall invasion, $H$. pylori presence, margin involvement or Isaacson's histological type, although the latter had a borderline statistical significance $(\mathrm{p}=0.056)$. As a result, the hazard ratio by means of Cox regression was not estimated.

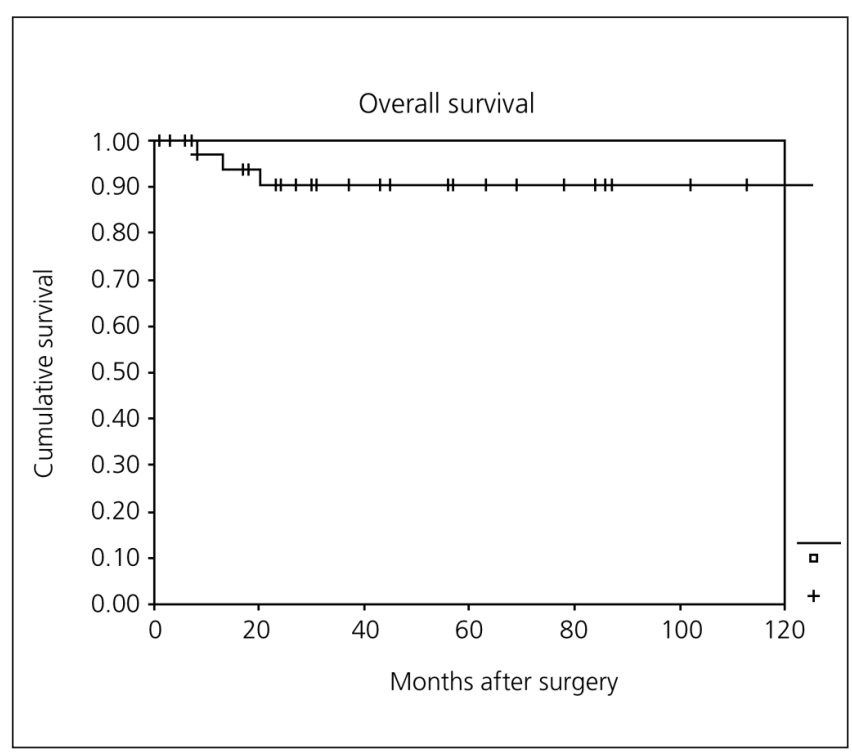

Fig. 1.- Survival probability after surgical excision. Probabilidad de supervivencia tras extirpación quirúrgica. 
Table I. Correlation between clinical-pathological variables and long-term survival

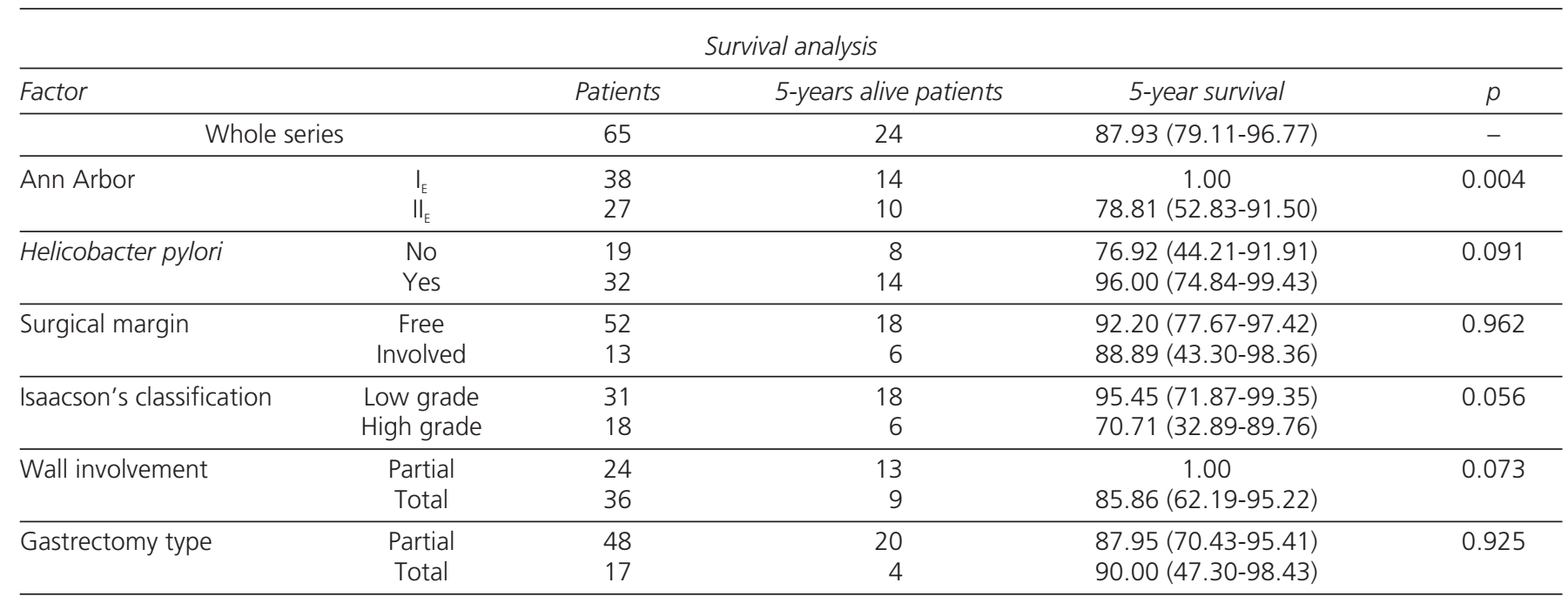

Patients with margin involvement and no other evidence of residual tumor did not show significantly poorer survival than patients having free borders. Although in positive-margin patients stage $\mathrm{II}_{\mathrm{E}}$ was more common (26.7\%) than in free-margin patients $(16.7 \%)$, differences were not significant (Chi-squared $=0.6,1 \mathrm{df}, \mathrm{p}=0.4$ ). No significant difference in tumor grade $-13.3 \%$ of $\mathrm{HG}, 25 \%$ of LGin positive margin patients (Chi-squared $=0.8 ; 1 \mathrm{df}, \mathrm{p}=$ 0.43 ) or in patients receiving postoperative CT-5 (45\%) of positive margin patients and $24(53.3 \%)$ of free margin patients (Chi-squared $=0.2,1 \mathrm{df}, \mathrm{p}=0.6$ )-was seen either. Of note, all positive-margin patients who did not receive postoperative $\mathrm{CT}$ are alive, although one had a pulmonary recurrence after 20 months. As a result, excision radicality did not influence prognosis, and no survival significant difference was appreciated between R0 and R1 excisions.

\section{DISCUSSION}

Our experience analysis reveals, first of all, a good long-term survival (higher than $87 \%$ after 5 years), which can be considered an excellent oncologic result.

Second, no prognostic influence was found for any of the studied histological factors, including some with a reported value as border involvement or histological type. This finding is surprising, especially since in our previous study (8), with a shorter follow-up and fewer cases, we found a prognostic value for border involvement and histological type. This suggests a statistical effect, which could also change in a future analysis with longer followup or inclusion of new cases. However, other investigators found gastric wall involvement to be of prognostic value $(10,13,15)$, although Koch et al. (20) found no prognostic influence for histological grade. The absence of any prognostic value in surgical margin involvement is surprising, although most patients $(54.5 \%)$ did not receive additive CT or RT. As a result, radical excision (R0), according to the criteria used in carcinomas, was not associated with a significantly longer survival than excisions leaving microscopic residual tumor (R1). The small number of cases with macroscopic residual tumor (R2) precludes an assessment of influence. This study therefore does not support radical excision but only macroscopic tumor removal. In other works, excision without residual tumor has been associated with better long-term survival rates $(10,12,15,21)$.

The classical indications of surgery for GL were diagnosis, staging, and treatment. Proper staging is presently achieved by means of computed tomography, endoscopic ultrasounds, and positron emission tomography (7), and therefore there is no longer a surgical indication. Although endoscopy has for a long time permitted diagnosis in most cases, a histological diagnosis cannot be achieved in some patients in spite of multiple biopsies. These cases will need a surgical procedure. It may be performed using a laparoscopic approach but a whole-thickness stomach biopsy is necessary, which would be more safely performed by means of an open procedure. It is possible that no additional surgery need be performed, and that the patient is treated with CT alone. However, our own data and those from other works (9-12) agree that surgical excision is still a good therapeutic option (Table II), with survival rates of 82 and $64 \%$ after 5 and 10 years, respectively, which is a comparable outcome to that of non-surgical treatment (7). However, although non-surgical therapy-related mortality rate is lower, and even nil in some series (5), it can be as high as 6\% (3). Cases of bleeding or perforation-spontaneous or CT-induced-are less controversial since surgical excision is mandatory in most cases. It does not seem logical to perform a simple suture and then continue therapy if the tu- 
Table II. Results of some recent, relevant surgical series

\begin{tabular}{|c|c|c|}
\hline \multicolumn{3}{|c|}{ Surgical results in gastric lymphoma } \\
\hline Author & Survival & Mortality \\
\hline Vaillant et al. (12) & $\begin{array}{l}94 \% \text { (5 years) LG } \\
89 \% \text { ( } 5 \text { years) HG }\end{array}$ & 0 \\
\hline Bartlett et al. (11) & $\begin{array}{l}100 \%(10 \text { years }) I_{E} \\
82 \%(10 \text { years }) \|_{E}\end{array}$ & 0 \\
\hline Fischbach et al. (9) & $\begin{array}{l}89-96 \% \text { * (2 years) LG } \\
83-88 \% \text { * (2 years) HG }\end{array}$ & $1.5 \%$ \\
\hline Kodera et al. (10) & $\begin{array}{l}80 \% \text { ( } 5 \text { years }) \\
70 \% \text { (10 years })\end{array}$ & $2.4 \%$ \\
\hline Present series & $87.9 \%$ (5 years) & $9.2 \%$ \\
\hline
\end{tabular}

LG: low-grade lymphoma; HG: high-grade lymphoma; *: numbers represent different risk groups.

mor can be excised in patients with acceptable surgical risks. Nevertheless, the frequency of such complications is quite low in recent studies $(5,20,22,23)$ : $0-3.5 \%$ of perforations and $0-7.4 \%$ of hemorrhages. Uncommon cases presenting with intestinal obstruction unresponsive to high-dose corticosteroids are also a surgical indication (7).

The aim of this work is not to discuss whether the best long-term survival is achieved with surgical or chemotherapeutic treatment. Similar outcomes have been reported in several studies for patients treated by CT or chemo-radiotherapy (CRT), and for those treated by CT or RT associated with surgery, thus suggesting that surgery does not improve CT or CRT results $(5,7,20,23,24)$. In one work (5), a superiority of CT over surgery is suggested, although the poor results reported in the arms including surgery make it difficult to admit a real advantage for CT. In our series of surgically treated GL, long-term survival is, of note, remarkably high $-87 \%$ after 5 years-, although the mortality rate is not negligible. An additional advantage of surgery is the diminished local recurrence rate $(20,25)$. Nevertheless, the actual trend is to treat GL with CT or CRT, and reserve surgery for residual disease or unresponsiveness cases $(3,4,7)$, which are estimated at 7-18\% (3-5).

Another therapeutic option for GL lymphomas is $H$. pylori eradication therapy. H. pylori infection leads to an active chronic inflammation of the gastric mucosa, which can induce the formation of organized lymphoid tissue in the stomach and the subsequent development of a lymphoma $(2,26)$. In fact, several epidemiological and molecular data support the relationship between $H$. pylori infection and GL development as the detection of the MALT lymphoma B-cell clone in $H$. pylori-associated chronic gastritis that precedes the lymphoma, and the fact that the growth of gastric MALT lymphoma cells can be stimulated by heat-killed $H$. pylori (26).
The frequency of $H$. pylori in our series is in the reported range of $62-96 \%$ for LG and $52-79 \%$ for HG lymphomas (2), which is one of the main arguments in favor of its etiopathogenic relationship with MALT lymphoma. Although high lymphoma remission rates with eradication therapy alone have been reported $(6,12,27,28)$, unresponsiveness is possible, especially if one or more of the following are present: HG histology (27), perigastric lymphadenopathy (28), tumor not confined to the mucosa (29) or presence of $\mathrm{t}(11 ; 18)(\mathrm{q} 21 ; \mathrm{q} 21)$ translocation (26). Non-responders to eradication therapy usually respond to RT or CT, although another option is surgery $(7,29)$.

Some aspects of molecular genetics with importance from a diagnostic and prognostic point of view are currently known. Three types of translocations are specifically associated with MALT lymphoma: $t(11 ; 18)(\mathrm{q} 21 ; \mathrm{q} 21)$, $\mathrm{t}(1 ; 14)(\mathrm{p} 22 ; \mathrm{q} 32)$, and $\mathrm{t}(14 ; 18)(\mathrm{q} 32 ; \mathrm{q} 21)$. Other genetic alterations are also observed with different frequencies such as trisomies 3,12 and 18, p53 loss of heterozygosity/mutation, p15 and p16 promoter methylation, and fas gene mutation. (26). In GL, $\mathrm{t}(11 ; 18)(\mathrm{q} 21 ; \mathrm{q} 21)$ is more frequently seen in cases showing spread to regional nodes or distant sites versus those confined to the stomach (26). These patients do not usually respond to $H$. pylori eradication therapy (26).

In conclusion, although we consider non-surgical therapy-CT-RT, H. pylori eradication-the treatment of choice, we think there are potential surgical indications such as absence of histological diagnosis, incidental findings, CT complications, or treatment failure. Surgeons must be aware that surgical treatment provides excellent longterm survival with a high local-control rate; therefore, they must have not doubts concerning the performance of gastrectomy in the above-mentioned circumstances.

\section{REFERENCES}

1. Ullrich A, Fischbach W, Blettner M. Incidence of gastric B-cell lymphomas: a population-based study in Germany. Ann Oncol 2002; 13: 1120-7.

2. Boot H, De Jong D. Gastric lymphoma: the revolution of the past decade. Scand J Gastroenterol 2002; 37 (Supl. 236): 27-36.

3. Maor MH, Velasquez SF, Fuller LM, Silvermintz KB. Stomach conservation in stages IE and IIE gastric non-Hodgkin's lymphoma. J Clin Oncol 1990; 8: 266-71.

4. Liu HT, Hsu Ch, Chen CL, Chiang IP, Chen LT, Chen YC, et al. Chemotherapy alone versus surgery followed by chemotherapy for stage I/IIE large-cell lymphoma of the stomach. Am J Hematol 2000; 64: 175-9.

5. Avilés A, Nambo MJ, Neri N, Huerta-Guzmán J, Cuadra I, Alvarado I, et al. The role of surgery in primary gastric lymphoma: results of a controlled clinical trial. Ann Surg 2004; 240: 44-50.

6. Stolte M, Bayerdorffer E, Morgner A, Alpen B, Wundisch T, Thiede C, et al. Helicobacter and gastric MALT lymphoma. Gut 2002; 50 (Supl. 3): III19-24.

7. Yoon SS, Coit DG, Portlock CS, Karpeh MS. The diminishing role of surgery in the treatment of gastric lymphoma. Ann Surg 2004; 240: 28-37.

8. Rodríguez-Sanjuán JC, Álvarez-Cañas C, Casado F, García-Castrillo L, Casanova D, Val-Bernal F, et al. Results and prognostic factors in stage IE-IIE primary gastric lymphoma after gastrectomy. J Am Coll Surg 1999; 188: 296-303. 
9. Fischbach W, Dragosics B, Kolve-Goebeler ME, Ohmann C, Greiner A, Yang Q, et al. Primary gastric B-cell lymphoma: results of a prospective multicenter study. Gastroenterology 2000; 119: 1191-202.

10. Kodera Y, Nakamura S, Yamamura Y, Shimizu Y, Torii A, Hirai T, et al. Primary gastric B-cell lymphoma: audit of 82 cases treated with surgery and classified according to the concept of mucosa-associated lymphoid tissue lymphoma. World J Surg 2000; 24: 857-62.

11. Bartlett DL, Karpeh MS Jr, Filippa DA, Brennan MF. Long-term follow-up after curative surgery for early gastric lymphoma. Ann Surg 1996; 223: 53-62.

12. Vaillant JC, Ruskoné-Fourmestraux A, Aegerter P, Gayet B, Rambaud JC, Valleur P, et al. Management and long-term results of surgery for localized gastric lymphomas. Am J Surg 2000; 179: 216-22.

13. Taal BG, Boot H, van Heerde P, de Jong D, Hart AAM, Burgers JMV. Primary non-Hodgkin lymphoma of the stomach: endoscopic pattern and prognosis in low versus high grade malignancy in relation to the MALT concept. Gut 1996; 39: 556-61.

14. Nakamura S, Akazawa K, Yao T, Tsuneyoshi M. Primary gastric lymphoma. A clinicopathologic study of 233 cases with special reference to evaluation with the MIB-1 index. Cancer 1995; 76: 1313- 24.

15. Radaszkiewicz T, Dragosics B, Bauer P. Gastrointestinal malignant lymphomas of the mucosa-associated lymphoid tissue: factors relevant to prognosis. Gastroenterology 1992; 102: 1628-38.

16. Dawson IMP, Cornes JS, Morson BC. Primary malignant lymphoid tumours of the intestinal tract. Br J Surg 1961; 49: 80-9.

17. Carbone PP, Kaplan HS, Musshoff K, et al. Report of the committee on Hodgkin's disease staging classification. Cancer Res 1971; 31: 1860-1.

18. Rodríguez-Sanjuán JC, Echevarría S, Álvarez-Cañas C, Naranjo A. Primary gastric lymphoma in an H.I.V.-Infected patient (Letter). J AIDS Hum Ret 1996; 13: 467-8.

19. Isaacson PG, Spencer J, Wright DH. Classifying primary gut lymphomas. Lancet 1988; ii: 1148-9.

20. Koch P, Del Valle F, Berdel WE, Willich NA, Reers B, Hiddemann
W, et al. Primary gastrointestinal non-Hodgkin's lymphoma: II. Combined surgical and conservative or conservative management only in localized gastric lymphoma - results of the prospective German Multicenter Study GIT NHL 01/92. J Clin Oncol 2001; 19: 3874-83.

21. Ruskoné-Fourmestraux A, Aegerter P, Delmer A, Brousse N, Galian $\mathrm{A}$, Rambaud JC and the group d'etude des lymphomes digestifs. Primary digestive tract lymphoma: a prospective multicentric study of 91 patients. Gastroenterology 1993; 105: 1662-71

22. Maisey N, Norman A, Prior Y, Cunningham D. Chemotherapy for primary gastric lymphoma: does in-patient observation prevent complications? Clin Oncol (R Coll Radiol) 2004; 16: 48-52.

23. Schmidt WP, Schmitz N, Sonnen R. Conservative management of gastric lymphoma: the treatment option of choice. Leuk Lymphoma 2004; 45: 1847-52.

24. Avilés A, et al. Is surgery necessary in the treatment of primary gastric non-Hodgkin lymphoma? Leuk Lymphoma 1991; 5: 365-9.

25. Ferreri AJ, Cordio S, Paro S, Ponzoni M, Freschi M, Veglia F, et al. Therapeutic management of stage I-II high-grade primary gastric lymphomas. Oncology 1999; 56: 274-82.

26. Isaacson PG, Du MQ. Gastrointestinal lymphoma: where morphology meets molecular biology. J Pathol 2005; 205: 255-74.

27. De Jong D, Vyth-Dreese F, Dellemijn T, Verra N, Ruskoné-Fourmestraux A, Lavergne-Slove A, et al. Histological and immunological parameters to predict treatment outcome of Helicobacter pylori eradication in low-grade gastric MALT lymphoma. J Pathol 2001; 193: $318-24$

28. Levy M, Copie-Bergman C, Traulle C, Lavergne-Slove A, Brousse N, Flejou JF, et al. Conservative treatment of primary gastric low-grade B-cell lymphoma of mucosa-associated lymphoid tissue: predictive factors of response and outcome. Am J Gastroenterol 2002; 97: 292-7.

29. Nakamura S, Matsumoto T, Suekane H, Takeshita M, Hizawa K, Kawasaki M, et al. Predictive value of endoscopic ultrasonography for regression of gastric low grade and high grade MALT lymphomas after eradication of Helicobacter pylori. Gut 2001; 48: 454-60. 